\title{
EMPLOYMENT AFTER RENAL TRANSPLANTATION VS. THE HEALTH LOCUS OF CONTROL AND THE QUALITY OF LIFE
}

\author{
MARTA GRUBMAN-NOWAK ${ }^{1}$, ALICJA DĘBSKA-ŚLIZIEN² ${ }^{2}$, and MARCIN RENKE ${ }^{1}$ \\ Medical University of Gdańsk, Gdańsk, Poland \\ ${ }^{1}$ Clinic of Occupational, Metabolic and Internal Diseases \\ ${ }^{2}$ Department of Nephrology, Transplantology and Internal Diseases
}

\begin{abstract}
Objectives: The aim of the presented study was to compare the health locus of control (HLC) between employed and unemployed patients after kidney transplantation (KT), and to investigate the relationship between HLC and the quality of life (QoL). Material and Methods: The study group consisted of $101 \mathrm{KT}$ patients and the control group of 60 hemodialysis (HD) patients. The applied methods were: the Multidimensional Health Locus of Control Questionnaire (MHLC), the WHO Quality of Life Questionnaire (WHOQoL-BREF), and a survey collecting information on the socio-demographic status and work experience. Results: Overall, 57.5\% of KT patients were employed and $42.5 \%$ were unemployed. In the HD group, $25 \%$ were employed and $71 \%$ were unemployed, while $4 \%$ did not disclose their employment status. The unemployed KT patients, in comparison with the employed ones, presented a higher feeling of the impact of chance on their health (unemployed $\mathrm{M} \pm \mathrm{SD} 23.68 \pm 6.59$; employed $\mathrm{M} \pm \mathrm{SD} 21.02 \pm 4.57$ ) and a lower level of QoL on the Somatic Scale (unemployed Me $=14.00, \mathrm{IQR}=3.00$; employed $\mathrm{Me}=1450, \mathrm{IQR}=3.00$ ) and the Environmental Scale (unemployed $\mathrm{M} \pm \mathrm{SD} 15.39 \pm 2.83$; employed $\mathrm{M} \pm$ SD 16.85 \pm 3.24 ). In the employed KT group, the Internal Control Scale (MHLC) correlated with all QoL scales (the Somatic Scale: $\mathrm{r}=0.292, \mathrm{p}=0.036$; the Psychological Scale: $\mathrm{r}=0.455, \mathrm{p}=0.001$; the Social Scale: $\mathrm{r}=0.304, \mathrm{p}=0.029$; and the Environmental Scale: $r=0.307, p=0.027)$. In the unemployed KT group, the Internal Control Scale (MHLC) correlated significantly with the Somatic Scale ( $r=0.396$, $\mathrm{p}=0.013)$ and the Psychological Scale $(\mathrm{r}=0.374, \mathrm{p}=0.019)$. Conclusions: The employed KT patients have a higher level of independence, with results indicating a strong internal type. Additionally, the working patients assess their QoL better, both in terms of their health condition and the organization of satisfying environment. The obtained knowledge about the psychological characteristics of KT patients may be useful for the occupational activation programs and psycho-education for those with weaker predispositions. Int J Occup Med Environ Health. 2022;35(1):53-62
\end{abstract}

Key words: quality of life, hemodialysis, health locus of control, health behaviors, employment, kidney transplantation

\section{INTRODUCTION}

Chronic kidney disease (CKD) is currently one of the world's main civilization diseases. In Poland, epidemiological studies indicate that around 4 million Poles suffer from CKD, and in the world this number may even reach 600 million [1]. End-stage renal disease (ESRD) is associated with long-term sick leave, burdensome hemodialysis procedures and, as a consequence, the inability to partici- pate in paid work. The most effective form of therapy for ESRD is kidney transplantation (KT). After undergoing a KT procedure, patients are expected to return to full activity, including work.

Authors of different studies have indicated that professional activity may be associated with greater survival of the transplanted organ. Often, however, return to work is a challenge for the patients. People after KT live

Received: October 24, 2020. Accepted: May 12, 2021

Corresponding author: Marta Grubman-Nowak, Medical University of Gdańsk, Clinic of Occupational, Metabolic and Internal Diseases, Powstania Styczniowego 9b, 81-519 Gdynia, Poland (e-mail: mgrubman@gumed.edu.pl). 
with a diagnosis of chronic disease and regularly experience health complications connected with immunosuppressive therapy, a risk of organ rejection, and associated diseases such as diabetes, cancer or osteoporosis. These factors may limit the possibilities of returning to various social roles and can affect the physical and mental well-being of an individual and their quality of life (QoL) [2].

Looking at the relationship between various factors related to professional activity, many authors suggest that it may be associated with younger age ( $<50$ years of age), gender (a higher employment rate among men), a higher level of education and a lack of concomitant diseases [3-6]. Most reports related to KT refer to some objective factors affecting QoL, such as pain, health, the body mass index, and how they translate into professional activity [4]. However, few studies deal with the analysis of subjective factors and their impact on returning to work. These are such factors as a subjective assessment of the disease, a poor assessment of perceived physical fitness, and disability.

For transplant recipients, the sense of physical constraints may be a barrier to take on valued social roles and activities. In addition, results of different research on the professional activity of people suffering from chronic diseases have shown that there is a relationship between self-esteem, the locus of control, the readiness to work and going back to occupational activity $[5,6]$. Millet and Sanberg [7] have shown in their research that an internal sense of control positively correlates with the status of work after a long period off work. Nazanin et al. [4] have also suggested that education above the secondary level and living with others may create conditions conducive to participation in work after KT. On the other hand, a poor assessment of mental and physical health may result in the lack of readiness to take up professional activity. Moreover, post-transplant experiences, associated with unpredictable episodes of organ rejection or infection, can reduce patients' internal sense of control and negatively affect their work engagement $[4,8-12]$.

The results of different studies indicate that the number of professionally active patients during the hemodialysis therapy (HD) is very low, ranging $10-30 \%$ depending on the studied population [13]. The range of employment statistics after KT, on the other hand, is very widespread and causes a lot of discussion and controversy [14]. For example, the percentage of working patients after successful KT procedures in the USA ranges 30-40\% [10], while it amounts to $40 \%$ in Finland [5], and to $67 \%$ in the Netherlands [13]. The discrepancies between these results are significant and may occur due to differences in defining the employment category and heterogeneity of the studied groups, taking into account demographic and clinical characteristics [5]. Despite the diversity of statistics, what is common is the fact that a large proportion of the patient population after KT does not return to work despite the objective potential.

The aim of the present study was to identify a specific psychological profile of those patients who decide to go back to work after KT. The goal was to compare the assessment of the health locus of control (HLC) between the employed and unemployed patients after KT. An additional aim was to investigate the relationship between HLC and the subjective assessment of QoL in the context of employment after KT.

\section{MATERIAL AND METHODS}

The research was conducted in February 2016-March 2019. The participation in the study was voluntary and it served as part of a dissertation project. The study was accepted by the Bioethics Committee of the Medical University. The participants were 161 patients from the following clinics:

- the Nephrological Outpatient Clinic, Transplant Medicine Ward - a hemodialysis station, 
- the Department of Transplantology, Nephrology and Internal Diseases.

The study group consisted of 101 patients after KT and the control group of $60 \mathrm{HD}$ patients. The KT group was additionally divided into subgroups based and the occupational activity. The inclusion in the study was based on the age group ranging 18-65 years both in the study and control groups. In the KT group, an additional condition was the passing of $\geq 1$ year after surgery.

The following methods were applied:

- the Multidimensional Health Locus of Control Questionnaire (MHLC; K.A. Wallston, B.S. Wallston and R. De Vellis; the Polish adaptation by Z. Juczyński) [15] an 18-item questionnaire measuring beliefs that the source of HLC may be related to primarily internal control (Scale I), the impact of chance (Scale C), or the control of powerful others (Scale P);

- the WHO Quality of Life Questionnaire (WHOQoLBREF; the WHOQoL Group) - the Polish version of the WHO questionnaire assessing QoL. The questionnaire measures 4 QoL domains: D1 - the Somatic Scale, D2 - the Psychological Scale, D3 - the Social Scale, and D4 - the Environmental Scale [16,17];

- a general survey collecting information on the sociodemographic status and work experience.

\section{Statistical analysis}

The statistical analysis included basic descriptive statistics, Shapiro-Wilk tests and Student's t-test for independent samples, and the Mann-Whitney U test. Correlation analyses were conducted using Pearson's $r$ coefficient. The statistical significance was set at classic $\alpha=0.05$. The data taken into account were based on 161 sets of questionnaires, with the materials obtained from 12 participants having been rejected due to missing data. The analysis included differences between the mean values of measured variables between the KT and HD groups, and in the
KT subgroups (employed and unemployed). Correlations between the subscales of MHLC and WHOQoL-BREF were also carried out. Additionally, the qualitative interpretation of the MHLC subscales was performed in all of the groups.

\section{RESULTS}

\section{Characteristics of the study group}

The study group consisted of 101 patients after KT: 61 men and 40 women. The average age of the participants was 48 years. While $57.5 \%$ of the surveyed declared that they were professionally active, the remaining $42.5 \%$ did not work. The average seniority among professionally active people was 24 years, compared to 15 years in the group of unemployed people. The average time since KT surgery was 7.8 years. Detailed characteristics are presented in Table 1.

The level of education in the group of professionally active patients after KT was distributed as follows: $32 \%$ of people with higher education, $36 \%$ of patients with secondary or post-secondary education, and $29 \%$ of those with vocational education (Table 1).

In the group of unemployed patients after KT, 55\% had vocational education, $25 \%$ secondary education, $9 \%$ higher education, and $9 \%$ primary education. In the group of employed people, $50 \%$ had a disability certificate, while $29 \%$ used the granted benefits. Among the unemployed patients after KT, $62 \%$ declared that they had a disability certificate, while $58 \%$ of patients in this group used financial benefits (Table 1).

\section{Characteristics of the control group}

Overall, $60 \mathrm{HD}$ patients were examined, of whom 39 were men and 21 were women. Only $25 \%$ of the people involved in this group were professionally active while $71 \%$ did not work. The average duration of HD was 4 years. A detailed summary of the characteristics of the HD group is presented in Table 1. 
Table 1. Characteristics of the examined groups (employed and unemployed patients after kidney transplantation [KT]) and the control group (patients undergoing hemodialysis) in the study conducted in February 2016-March 2019 in the Nephrological Outpatient Clinic, Transplant Medicine Ward a hemodialysis station and the Department of Transplantology, Nephrology and Internal Diseases, Gdańsk, Poland

\begin{tabular}{|c|c|c|c|}
\hline \multirow{3}{*}{ Variable } & \multicolumn{3}{|c|}{$\begin{array}{l}\text { Participants } \\
(\mathrm{N}=161)\end{array}$} \\
\hline & \multicolumn{2}{|c|}{$\begin{array}{l}\text { study group } \\
(\mathrm{N}=101)\end{array}$} & \multirow{2}{*}{$\begin{array}{l}\text { control group } \\
\quad(N=60)\end{array}$} \\
\hline & $\begin{array}{l}\text { employed KT patients } \\
(\mathrm{N}=58,57.5 \%)\end{array}$ & $\begin{array}{c}\text { unemployed KT patients } \\
(\mathrm{N}=43,42.5 \%)\end{array}$ & \\
\hline Age [years] (M) & 47.2 & 48.9 & 59 \\
\hline \multicolumn{4}{|l|}{ Gender [n (\%)] } \\
\hline male & $39(67.2)$ & $22(51.2)$ & $39(67.2)$ \\
\hline female & $19(32.8)$ & $21(48.8)$ & $21(35)$ \\
\hline \multicolumn{4}{|l|}{ Marital status [n (\%)] } \\
\hline married & $39(67.2)$ & $33(76)$ & $35(58)$ \\
\hline divorced & $10(17.2)$ & $3(6.9)$ & $6(10)$ \\
\hline widow/widower & $2(3.4)$ & 0 & $5(8.3)$ \\
\hline single & $3(5.1)$ & $5(11.6)$ & $11(18.3)$ \\
\hline no data & $4(6.8)$ & $2(4.6)$ & \\
\hline \multicolumn{4}{|l|}{ Education [n (\%)] } \\
\hline high & $19(32)$ & $4(9)$ & \\
\hline secondary & $21(36)$ & $11(25)$ & \\
\hline vocational & $17(29)$ & $24(55)$ & \\
\hline elementary & 0 & $4(9)$ & \\
\hline \multicolumn{4}{|l|}{ Occupational activity [n (\%)] } \\
\hline employed & & & $15(25)$ \\
\hline unemployed & & & $43(71)$ \\
\hline no data & & & $2(4)$ \\
\hline \multicolumn{4}{|l|}{ Social benefits [n (\%)] } \\
\hline disability certificate & $29(50)$ & $27(62)$ & \\
\hline retirement from work & $1(1.7)$ & $25(58)$ & \\
\hline pension due disability & $17(29)$ & $6(13)$ & \\
\hline Time since KT surgery [years] (M) & 8 & 7.5 & \\
\hline Hemodialysis duration [years] (M) & & & 4 \\
\hline
\end{tabular}

\section{Differences between HLC and QoL}

It was found that the group of patients undergoing KT compared to HD patients obtained lower results on MHLC Scale C: $\mathrm{HD}-\mathrm{M} \pm \mathrm{SD} 24.07 \pm 6.14 ; \mathrm{KT}-\mathrm{M} \pm \mathrm{SD} 22.13 \pm 5.63$, and higher QoL on WHOQoL-BREF Scale D1: HD $\mathrm{M} \pm$ SD 12.14 $\pm 2.73 ; \mathrm{KT}-\mathrm{M} \pm \mathrm{SD} 14.27 \pm 3.55$ (Table 2). This means that people from the KT group, compared to the group of HD patients, believed that their health was less 
Table 2. Comparison of the significant results of the health locus of control and the quality of life between the patients after kidney transplantation (KT) and after hemodialysis (HD) in the study conducted in February 2016-March 2019 in the Nephrological Outpatient Clinic, Transplant Medicine Ward a hemodialysis station and the Department of Transplantology, Nephrology and Internal Diseases, Gdańsk, Poland

\begin{tabular}{|c|c|c|c|c|c|c|c|c|}
\hline \multirow[t]{2}{*}{ Scales } & \multicolumn{2}{|c|}{$\begin{array}{l}\text { HD patients } \\
(\mathrm{N}=60)\end{array}$} & \multicolumn{2}{|c|}{$\begin{array}{l}\text { KT patients } \\
(\mathrm{N}=99)\end{array}$} & \multirow[t]{2}{*}{$\mathrm{t}$} & \multirow[t]{2}{*}{$\mathrm{p}$} & \multirow[t]{2}{*}{$95 \% \mathrm{Cl}$} & \multirow[t]{2}{*}{$\mathrm{d}$ Cohen } \\
\hline & M & SD & M & SD & & & & \\
\hline MHLC:C & 24.07 & 6.14 & 22.13 & 5.63 & 2.01 & 0.047 & $-0.02-3.91$ & 0.46 \\
\hline WH0QOL-BREF: D1 & 12.14 & 2.73 & 14.27 & 3.55 & -3.88 & $<0.001$ & $-3.15-(-1.11)$ & 0.95 \\
\hline
\end{tabular}

C - the Impact of Chance Scale; D1 - the Somatic Scale; MHLC - the Multidimensional Health Locus of Control Questionnaire;

WHOQOL-BREF - the WHO Quality of Life Questionnaire.

$\mathrm{t}$ - Student's $\mathrm{t}$ test result.

Significance: $p<0.05$.

related to the impact of chance and their subjective assessment of QoL was higher in the context of their health state. The comparison of the results of employed and unemployed KT patients (Table 3) allowed to state that the working patients obtained significantly lower results on MHLC Scale C: unemployed - M \pm SD 23.68 \pm 6.59 ; - $\mathrm{M} \pm$ SD 21.02 \pm 4.57 , and they presented significantly higher QoL results on Scale D1: unemployed $\mathrm{Me}=14.00$, $\mathrm{IQR}=3.00$; employed $\mathrm{Me}=1450, \mathrm{IQR}=3.00$, and on Scale D4: unemployed - M \pm SD 15.39 \pm 2.83 ; employed - M \pm SD 16.85 \pm 3.24 of WHOQoL-BREF (Table 4). These results suggest that employed KT patients, compared to the unemployed ones, believed that their health was less related to the impact of chance, and they had a better assessment of their QoL in the context of their health status and environment.

\section{Health locus of control}

The employed patients after KT obtained high scores on Scale I $(\mathrm{M} \pm \mathrm{SD} 26.21 \pm 4.98)$, low scores on Scale $P$ $(\mathrm{M} \pm \mathrm{SD} 28.32 \pm 5.30)$, and low scores on Scale C $(\mathrm{M} \pm \mathrm{SD}$ 21.02 \pm 4.57 ). This configuration of results (high I, low $\mathrm{P}$ and low $\mathrm{C}$ ) creates a profile characterized as a strong internal type (Table 4).

The unemployed patients after KT obtained high scores on Scale I $(\mathrm{M} \pm \mathrm{SD} 28.10 \pm 4.99)$, low scores on Scale P
$(\mathrm{M} \pm \mathrm{SD} 29.30 \pm 4.79)$, and high scores on Scale $C(\mathrm{M} \pm \mathrm{SD}$ 23.68 \pm 6.59 ). This configuration of results (high $\mathrm{I}$, low $\mathrm{P}$ and high C) creates a profile characterized as a type that diminishes the influence of others (Table 5).

The patients from the HD group obtained low scores on Scale I $(\mathrm{M} \pm \mathrm{SD} 25.33 \pm 6.97)$, low scores on Scale $P$ $(\mathrm{M} \pm \mathrm{SD} 29.21 \pm 6.49)$, and high scores on Scale C $(\mathrm{M} \pm \mathrm{SD}$ $24.07 \pm 6.14$ ). This configuration of results (low I, low $\mathrm{P}$ and high $\mathrm{C}$ ) creates a profile characterized as a type increasing the impact of chance (Table 4).

\section{Relationships between HLC and QoL}

In the group of employed patients after KT, the results of Scale I of MHLC significantly correlated with those of Scale D1 ( $\mathrm{r}=0.292, \mathrm{p}=0.036$; a weak positive correlation), Scale D2 $(r=0.455, \mathrm{p}=0.001$; a moderate positive correlation ), Scale D3 ( $\mathrm{r}=0.304, \mathrm{p}=0.029$; a moderate positive correlation), and Scale D4 ( $\mathrm{r}=0.307, \mathrm{p}=0.027$; a moderate positive correlation) of WHOQoL-BREF. This means that the higher the internal locus of control, the higher the subjective assessment of all domains of QoL (Table 5).

In the group of unemployed patients after KT, the results of Scale I of MHLC were significantly associated with those of Scale D1 ( $\mathrm{r}=0.396, \mathrm{p}=0.013$; a moderate positive correlation) and Scale D2 $(\mathrm{r}=0.374, \mathrm{p}=0.019$; a moderate positive correlation) of WHOQoL-BREF. 


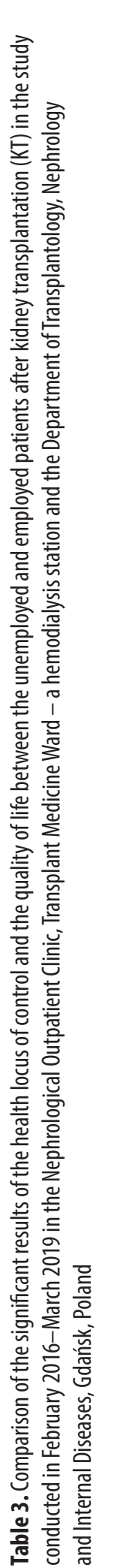

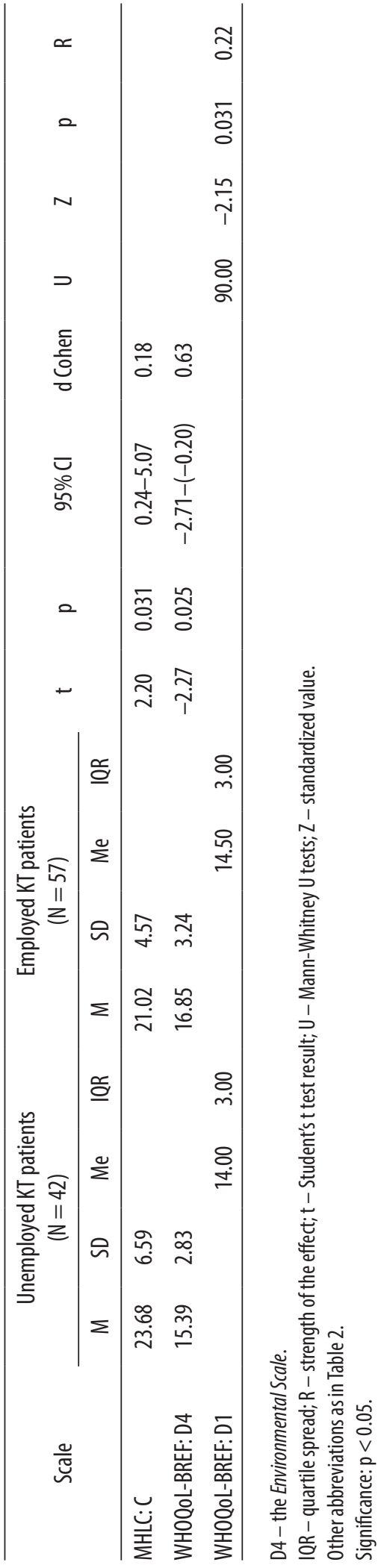

This means that the higher internal locus of control, the higher the assessment of QoL in the area of the physical condition and psychological functioning (Table 5).

In the HD patient group, Scale $P$ of MHLC significantly correlated with Scale D4 of WHOQoL-BREF ( $\mathrm{r}=0.381$, $\mathrm{p}=0.004 ;$ a moderate positive correlation). This means that the higher the sense of dependence on powerful others, the better the subjective assessment of environmental QoL (Table 5).

\section{DISCUSSION}

Authors of different research indicate that the return to work among patients after KT may be associated with a greater survival rate of the transplanted organ [2]. Very often, however, going back to work may be challenging for the patients.

According to authors of various studies, such factors as education or work experience before transplantation may predict the return to professional activity after KT $[3,4,6]$. A higher level of education is regarded as one of the employment predictors. Bohlke et al. [3] showed that working transplant recipients were better educated compared to the unemployed ones. Chisholm-Burns [18] suggested that a higher level of education might be associated with greater access to job offers. Better education, a good physical functioning, and lower levels of fatigue can affect employment independently of one another. The vast majority of authors of scientific reports also indicate that professional activity before transplantation increases the likelihood of returning to work [4].

The results of the presented research reflect the global results. In the group of patients after KT, the average work experience among professionally active people was 24 years, while seniority in the unemployed group was 15 years. The distribution of the levels of education also coincides with global literature. Education in the group of the employed patients after KT was higher than in the unemployed group. 
Table. 4. Configuration of the Multidimensional Health Locus of Control Questionnaire (MHLC) scales in the groups of employed and unemployed patients after kidney transplantation (KT), and in the general study group and control group, in the study conducted in February 2016-March 2019 in the Nephrological Outpatient Clinic, Transplant Medicine Ward - a hemodialysis station and the Department of Transplantology, Nephrology and Internal Diseases, Gdańsk, Poland

\begin{tabular}{|c|c|c|c|c|c|c|c|c|c|c|}
\hline \multirow{3}{*}{ MHLC } & \multicolumn{5}{|c|}{$\begin{array}{c}\text { Participants } \\
(\mathrm{N}=99)\end{array}$} & \multicolumn{5}{|c|}{$\begin{array}{l}\text { Participants } \\
(\mathrm{N}=159)\end{array}$} \\
\hline & \multicolumn{2}{|c|}{$\begin{array}{l}\text { unemployed } \\
(\mathrm{N}=42)\end{array}$} & \multicolumn{2}{|c|}{$\begin{array}{l}\text { employed } \\
(\mathrm{N}=57)\end{array}$} & \multirow[t]{2}{*}{$\mathrm{Me}$} & \multicolumn{2}{|c|}{$\begin{array}{l}\text { after HD } \\
(\mathrm{N}=60)\end{array}$} & \multicolumn{2}{|c|}{$\begin{array}{l}\text { after KT } \\
(\mathrm{N}=99)\end{array}$} & \multirow[t]{2}{*}{$\mathrm{Me}$} \\
\hline & M & SD & M & SD & & M & SD & $M$ & SD & \\
\hline MHLC:I & 28.10 & 4.99 & 26.21 & 4.98 & 26.00 & 25.33 & 6.97 & 27.00 & 5.05 & 26.00 \\
\hline MHLC: P & 29.30 & 4.79 & 28.32 & 5.30 & 30.00 & 29.21 & 6.49 & 28.73 & 5.09 & 30.00 \\
\hline MHLC:C & 23.68 & 6.59 & 21.02 & 4.57 & 22.00 & 24.07 & 6.14 & 22.13 & 5.63 & 22.00 \\
\hline
\end{tabular}

HD - hemodialysis; I - the Internal Control Scale; P - the Powerful Others Scale.

Other abbreviations as in Table 2.

Table 5. Correlations between the health locus of control and the quality of life in the group of employed patients and unemployed patients after kidney transplantation (KT) and hemodialysis (HD) patients in the study conducted in February 2016-March 2019 in the Nephrological Outpatient Clinic, Transplant Medicine Ward - a hemodialysis station and the Department of Transplantology, Nephrology and Internal Diseases, Gdańsk, Poland

\begin{tabular}{|c|c|c|c|}
\hline \multirow{3}{*}{ WHOQOL-BREF } & \multicolumn{3}{|c|}{ Multidimensional Health Locus of Control Questionnaire } \\
\hline & \multicolumn{2}{|c|}{ Internal Control Scale (I) } & \multirow{2}{*}{$\begin{array}{l}\text { Powerful Others Scale - after } \mathrm{HC} \\
\qquad(\mathrm{N}=60)\end{array}$} \\
\hline & $\begin{array}{l}\text { employed KT patients } \\
\qquad(\mathrm{N}=57)\end{array}$ & $\begin{array}{l}\text { unemployed KT patients } \\
\qquad(\mathrm{N}=42)\end{array}$ & \\
\hline \multicolumn{4}{|l|}{ D1 } \\
\hline$\rho$ Spearman's & 0.292 & 0.396 & 0.164 \\
\hline $\mathrm{p}$ & 0.036 & 0.013 & 0.232 \\
\hline \multicolumn{4}{|l|}{ D2 } \\
\hline r Pearson's & 0.455 & 0.374 & 0.132 \\
\hline $\mathrm{p}$ & 0.001 & 0.019 & 0.337 \\
\hline \multicolumn{4}{|l|}{ D3 } \\
\hline$\rho$ Spearman's & 0.304 & 0.203 & 0.078 \\
\hline $\mathrm{p}$ & 0.029 & 0.215 & 0.572 \\
\hline \multicolumn{4}{|l|}{ D4 } \\
\hline rPearson's & 0.307 & 0.060 & 0.381 \\
\hline$p$ & 0.027 & 0.545 & 0.004 \\
\hline
\end{tabular}

D2 - the Psychological Scale; D3 - the Social Scale.

Bolded $p<0.05$.

Other abbreviations as in Tables $2-4$.

The health aspect also seems to be an important factor for starting work. The unemployed declare weaker kidney function and limitations in their physical function- ing compared to the population of those who returned to work $[4,5,19]$. Other studies have shown that severe fatigue, not receiving benefits, and the side effects of 
immunosuppressants have a negative impact on returning to work after KT $[6,18]$.

Regarding the state of health, the results of the presented research revealed that $62 \%$ of unemployed people declared having a disability certificate, while more than a half of the patients included in this group benefited from financial services. Half of the working patients after KT had a disability certificate, while only one-third of those patients used the granted benefits. This results distribution in both groups may suggest that people from the inactive group may experience more negative somatic symptoms, weaker efficiency and worse overall health. In addition, HLC translates into a sense of feeling of capability in various areas of functioning. People's opinions on the state of health may be associated with an assessment of their own fitness, performance and, consequently, a sense of fitness for work. In addition, people with a high feeling of capability are perceived as more active in engaging in health-related activities. They are characterized by independence and a sense of responsibility for undertaking health-related behaviors, and a high level of commitment to these activities and maintaining wellbeing [15,21].

The presented research compared the results regarding HLC in KT patients in relation to their professional activity. The analysis showed that the non-working people had a higher level of the sense of impact of accidental events on their health compared to working people. Moreover, professionally active patients obtained a results profile indicating a strong internal type [20], which indicates a high feeling of internal control over their health status. This belief may translate into greater confidence in undertaking social activities after KT, such as continuing or taking up work.

In the group of employed patients after KT, a positive relationship between HLC and all QoL scales was distinguished. The strongest relationship occurred between Scale I and Scale D2. This means that the greater the sense of control and influence, the better the assessment of psychological well-being, which also extends to other areas of QoL.

In the group of unemployed patients, positive relationships were obtained between the internal HLC and 2 QoL scales - somatic and psychological. The configuration of these relationships again underlines the importance of the feeling of capability and influence on the course of events for a positive assessment of mental health and well-being.

In the presented research, a comparison of the average values between the groups of employed and unemployed patients after KT showed that working people evaluated their QoL better in 2 areas - somatic and environmental. This means that professionally active patients have a better opinion about their health and social status, social facilities and the environment they function in. On the one hand, Scale D4 translates into a better social status, which may be directly connected with job benefits. On the other hand, it also includes very important elements, such as social support networks, self-development possibilities, access to information, and freedom to choose activities related to leisure and recreation.

\section{CONCLUSIONS}

The presented work discusses issues related to CKD, which is currently considered one of the major civilization diseases in the world [1]. Professional activity is a very important element of rehabilitation after KT. Returning to work after organ transplantation is one of the main determinants of transplant success.

There is a gap in global literature related to the analysis of psychological predispositions of people after KT and their impact on the return to professional activity. In global studies, most researchers focus on health, fitness and socio-demographic data that can affect the return to work. Based on the results of independent research, the existence of specific psychological predispositions was 
identified in the group of working patients after KT. Professionally active patients after $\mathrm{KT}$, in comparison with the unemployed KT patients as well as HD patients, have a higher level of independence, as evidenced by the high level of internal HLC with the configuration of results indicating a strong internal type. Moreover, those patients assess their QoL better, both in terms of their health condition as well as the organization of a safe environment, material stability, the social status or having a support group. The results also indicate a direct positive relationship between the internal locus of control and a higher level of QoL assessment.

The obtained knowledge about the psychological predispositions of working KT patients can be used to establish occupational activation and psychological rehabilitation programs. Such training and psycho-education may be aimed at facilitating the return to daily activities for patients with weaker coping mechanisms and skills. The presented conclusions can also be used in the preparation of training programs for health workers, facilitating the identification of potential risk factors of maladaptive behaviors among patients in the early stages of treatment and providing them with appropriate support.

\section{REFERENCES}

1. Renke M, Parszuto J, Rybacki M, Wołyniec W, Rutkowski P, Walusiak-Skorupa J, et. al. [Chronic kidney disease - The relevant information for an occupational physician]. Med Pr 2018; 69(1):67-75, https://doi.org/10.13075/mp.5893.00624. Polish.

2. Muehrer R, Becker N. Life after transplantation: new transitions in quality of life and psychological distress. Seminars Dial. 2005;18(2):124-31, https://doi.org/10.1111/j.1525-139X. 2005.18214.x.

3. Bohlke M, Marini S, Gomes R, Terhorst L, Rocha M, Poli de Figueiredo C, et al. Predictors of employment after successful kidney transplantation - a population-based study. Clin Tranplant. 2008;22(4):405-10, https://doi.org/10.1111/ j.1399-0012.2008.00797.x.
4. Nazanin N, Heck C, Ross H. Factors related to participation in paid work after organ transplantation: perceptions of kidney transplant recipients. J Occup Rehabil. 2015;25:3851, https://doi.org/10.1007/s10926-014-9519-4.

5. Van der Mei S, Krol B, van Son W, de Jong P, Groothoff J, van den Heuvel W. Social participation and employment status after kidney transplantation: a systematic review. Qual Life Res. 2006;15:979-94, https://doi.org/10.1007/s11136-006-0045-5.

6. Van der Mei S, Kuiper D, Groothoff J, van den Heuvel W, van Son W, Brouwer S. Long-term health and work outcomes of renal transplantation and patterns of work status during the end-stage renal disease trajectory. J Occup Rehab. 2011;21:325-34, https://doi.org/10.1007/s10926-011-9317-1.

7. Millet P. Locus of control and its relation to working life: Studies from the fields of vocational rehabilitation and small firms in Sweden [disertation]. Luleå University of Technology Department of Human Work Sciences, Technical Psychology; 2005.

8. Booth C, Koppes L, van den Bossche S, Anema J, van der Beek A. Relation between perceived health and sick leave in employees with chronic illness. J Occup Rehabil. 2011;21: 211-9, https://doi.org/10.1007/s10926-010-9273-1.

9. Jansen D, Grootendorst D, Rijken R, Heijmans M, Kaptein A, Boeschoten E, et al. Pre-dialysis patients' perceived autonomy, self-esteem and labor participation: associations with illness perceptions and treatment perceptions. A crosssectional study. BMC Nephrol. 2010;11:35, https:/doi.org/ 10.1186/1471-2369-11-35.

10. McGee J, Jackson N, Slakey D. Disability and kidney transplantation in the United States. Clin Transplant. 2012;26(3): 377-81, https://doi.org/10.1111/j.1399-0012.2012.01612.x.

11. Slakey D, Rosner M. Disability following kidney transplantation: the link to medication coverage. Clin Tranplant. 2007;21: 224-8, https://doi.org/10.1111/j.1399-0012.2006.00629.x.

12. Engle D. Psychosocial aspects of the organ transplant experience: what has been established and what we need for the future. J Clin Psychol. 2001;57(4):521-41, https://doi.org/ 10.1002/jclp.1027. 
13. Helantera I, Haapio M, Koskinen P, Gronhagen-Riska C, Finne P. Employment of patients receiving maintenance dialysis and after kidney transplant: a cross-sectional study from Finland. Am J Kidney Dis. 2012;59(5):700-6, https:// doi.org/10.1053/j.ajkd.2011.08.025.

14. Eppenberger L, Hirt-Minkowski P, Dickenmann M. Back to work? Socioeconomic status after kidney transplantation. Swiss Med Wkly. 2015;145:w14169, https://doi.org/10. 4414/smw.2015.14169.

15. Juczyński Z. [Psychological tools in health promotion and psychology]. Warszawa: Pracownia Testów Psychologicznych Polskiego Towarzystwa Psychologicznego; 2012. Polish.

16. The WHOQOL Group. The world health organization Quality of Life assesment (WHOQOL): Position paper from the World Health Organisation. Soc Sci Med. 1995;41(10):1403-9, https://doi.org/10.1016/0277-9536(95) 00112-K.
17. The WHOQOL Group. Development of the WHOQOL Bref quality of life assessment. Psychol Med. 1998;28:551-8; https://doi.org/10.1017/S0033291798006667.

18. Chisholm-Burns M, Erickson S, Spivey C, Kaplan B. Healthrelated quality of life and employment among renal transplant recipients. Clin Transplant. 2012;26:411-7, https:// doi.org/10.1111/j.1399-0012.2011.01541.x.

19. Matas A, Lawson W, McHugh L, Gillingham K, Payne W, Dunn D, et al. Employment patterns after successful kidney transplantation. Transplantation. 1996;61(5):729-33.

20. Wallston BS, Wallston KA, Kaplan GD, Maides SA. The development and validation of the health related locus of control (HLC) scale. J Consult Clin Psychol. 1976;44(4):580-5, https://doi.org/10.1037/0022-006X.44.4.580.

21. Norman P. Health locus of control and health behaviour: an investigation into the role of health value and behavior-specific efficacy beliefs. Pers Individ Differ. 1994;18(2):213-8, https://doi.org/10.1016/0191-8869(94)00140-N.

This work is available in Open Access model and licensed under a Creative Commons Attribution-NonCommercial 3.0 Poland License - http://creativecommons.org/ licenses/by-nc/3.0/pl/deed.en. 